\title{
editorial
}

\section{MEDIFAM: un proyecto que ha merecido la pena}

\begin{abstract}
Hace
ace 15 años, de un grupo de médicos de familia, surgió la idea de realizar una publicación que sirviera a los intereses científicos de su colectivo, que contemplara todos los aspectos relevantes de su especialidad y aportara ideas para el desarrollo de la Atención Primaria. Como objetivos ineludibles nos propusimos además que tuviese un alto nivel de calidad, que fuese un instrumento para la formación en contenidos clínicos y en metodología de investigación y que reforzase el papel del médico de familia en el área sociosanitaria. Debía reflejar la realidad de la Atención Primaria y de la Medicina de Familia y contribuir tanto como fuese posible en su mejora.

Evidentemente ya existían publicaciones nacionales e internacionales dirigidas al mismo colectivo profesional y posiblemente con parecidas intenciones pero, no obstante, consideramos que ciertos aspectos eran claramente mejorables o simplemente no estaban suficientemente tratados.

A través de las diferentes secciones de esta nueva publicación, remarcábamos la necesidad de realizar investigación de calidad, la importancia de colaboración entre nuestra especialidad y el resto de especialidades para la adecuada atención de las patologías de nuestros pacientes, y la necesidad de conocer la dinámica familiar para el correcto desarrollo de nuestra función como médicos de familia. Con la sección de notas clínicas quisimos resaltar el contenido y el trabajo clínico de nuestra especialidad. Posteriormente, atendiendo a las necesidades formativas que fuimos identificando, incorporamos secciones para mejorar el aprendizaje de habilidades, técnicas y procedimientos o para realizar correctamente la valoración crítica de la práctica clínica.

Desde el principio, desde la fase en que sólo era una idea, hemos tenido la magnífica oportunidad de dirigir MEDIFAM. El trabajo, por qué no decirlo, ha sido inmenso, pero a pesar de ello no podemos hacer otra cosa que agradecer la oportunidad de haber podido realizarlo. Siempre ha sido un reto y en los más variados aspectos. Desde lograr la financiación durante los primeros años con múltiples negociaciones con la industria farmacéutica, pasando por la difícil relación con editoriales con el objetivo de lograr la calidad preservando y promoviendo los intereses científicos por encima de los comerciales, hasta la "dura" negociación con semFYC (negociar con 5 presidentes) para que MEDIFAM acabara siendo el Órgano de Difusión de la Sociedad. Todo esto, además de la dirección científica, ha sido de lo más enriquecedor.

Lo conseguido hasta aquí, evidentemente con el esfuerzo de todos, ha sido mucho: amplia difusión, participación como autores de médicos de familia con merecido reconocimiento y prestigio, contenidos atractivos y
\end{abstract}




\section{editorial}

útiles, inclusión en índices nacionales e internacionales (Excerpta, Scielo, Latindex, Ibex, Índice Médico Español), formato online con todo el contenido disponible de forma gratuita, y, desde hace 2 años, ser el Órgano de Difusión de semFYC. En el momento de escribir estas líneas $M E D I F A M$ se encuentra en proceso de evaluación para su inclusión en MEDLINE.

Lo mejor, sin ninguna duda, ha sido poder participar en el Consejo Editorial, un auténtico "Consejo de Amigos". Participar en sus debates, donde se han definido las líneas editoriales o se han discutido aspectos siempre importantes de nuestra especialidad o de Atención Primaria, pero especialmente tratar con todos los que han formado parte del Consejo Editorial ha sido un auténtico lujo, por ellos mismos, por su calidad humana y por sus siempre excelentes aportaciones. El trabajo de este grupo de personas, además de responder a los autores tras la corrección de sus trabajos, ha dado como resultado magníficas ideas y líneas de trabajo que han sido continuamente difundidas a través de la revista

Ahora, al menos por el momento, dejará de publicarse MEDIFAM. Según ARÁN Ediciones, las empresas de la industria farmacéutica que han sido nuestros máximos financiadores en los años previos mediante compra de páginas de publicidad, han retirado la financiación a la editorial para nuestra revista. No alcanzamos a entender esta situación cuando es una publicación que se dirige a más de 16.000 socios de semFYC. La verdad es que desconocemos las razones de fondo.

No queremos dejar de comentar lo difícil que resulta mantenerse "en este mundillo" cuando se pretende la absoluta independencia de los poderes e intereses editoriales y de los de la industria farmacéutica. Los dos mayores conflictos vividos durante estos años han estado en relación, el primero con la comunicación a un autor de la duplicación de su publicación, y el segundo con el rechazo de un artículo de diseño de original de investigación patrocinado por una empresa farmacéutica. Posiblemente, como resultado de este segundo conflicto, se crearon diferencias incompatibles entre nuestra manera de dirigir y los intereses editoriales y la consecuencia fue el tener que cambiar de editorial. Aunque parezca increíble cosas como estas pasan y los intereses científicos resulta que a veces son los "últimos" intereses para la industria farmacéutico o la industria editorial.

Ante estas circunstancias, la Sociedad Medifam ha ofertado, mediante distintas fórmulas, la revista MEDIFAM a semFYC, con el convencimiento de que era para semFYC una magnífica oportunidad disponer de un órgano de expresión independiente. Este ofrecimiento, tras ser valorada la propuesta por la Junta Directiva, no ha sido aceptado. Lamentamos profundamente esta decisión porque ello supone para semFYC, según nuestro criterio, no tener como publicación oficial una que dependa exclusivamente de la Sociedad y que pueda funcionar y mantenerse al margen de intereses diferentes a los estrictamente científicos.

Desde estas líneas de despedida queremos agradecer especialmente el trabajo desinteresado del Comité de Expertos, muchos de sus miembros 


\section{editorial}

colaborando desde el inicio de MEDIFAM, porque ha sido uno de los pocos comités que realmente ha trabajado como su denominación indica, y porque con su magnífica participación ha permitido siempre una cuidadosa a la vez que exhaustiva evaluación de los trabajos recibidos.

A todos los autores que han querido participar con MEDIFAM, gracias. Hemos tenido la oportunidad de aprender mucho de la lectura y evaluación de todos los artículos enviados. Las revistas sólo existen porque participan los autores mediante el envío de sus trabajos. A todos, se hayan aceptado o no sus manuscritos, gracias por mantener un proyecto que tanto nos ha ilusionado durante estos años.

Queremos mostrar nuestro más sincero agradecimiento a las directoras editoriales y secretarias de redacción que ha tenido MEDIFAM. Nuestro más agradecido recuerdo y reconocimiento para Yolanda y Marisa en IDEPSA y $\mathrm{M}^{\mathrm{a}}$ Dolores y Rosa en ARÁN, que, sin figurar en ningún sitio, han sido fundamentales en el buen funcionamiento de la revista.

Sería injusto si no agradeciéramos a nuestras esposas (Helena, $\mathrm{M}^{\mathrm{a}}$ Ángeles y Alicia) y a nuestros hijos (Daniel, Verónica, Laia y Jaime) su apoyo incondicional, especialmente en los momentos difíciles y el tiempo que nos "prestaron" para que dedicáramos a MEDIFAM del que sin duda les correspondía.

Durante estos años hemos intentado mantener un alto nivel de exigencia, y ello ha significado tener que rechazar muchos manuscritos (la media de aceptación de trabajos originales de investigación ha sido del 33\%). Siempre hemos justificado debidamente nuestra decisión, con marcado interés formativo como ha sido el espíritu de MEDIFAM, pero, como siempre es posible, si en algún caso nos hemos equivocado pedimos disculpas a quien se haya podido sentir minusvalorado o tratado injustamente.

Si algo hemos pretendido es que esta revista fuese realmente útil para los médicos de familia. Para ello era necesario que además de los contenidos adecuados a las necesidades de formación, de la aportación de ideas para el mejor desarrollo de la especialidad y de la Atención Primaria, tuviese la calidad imprescindible para ser valorada y reconocida como fuente de opinión y formación. Esperamos haber conseguido la aceptación de la publicación por los lectores, la confianza de los autores y la participación ilusionada de todos los que de una u otra forma han colaborado en este tiempo con MEDIFAM. Y en todo caso ¡Gracias, lectores!, por habernos otorgado durante todos estos años vuestro reconocimiento. 